\title{
Urethane-Modified Boron Containing Polyesteramide of Phthalic Acid from Jatropha Curcas Seed Oil
}

\author{
GHAZALA IMRAN* and S. A. AHMAD
}

Natural Product and Polymer Research Laboratory, Department of Chemistry, G.F. College (M.J.P. Rohilkhand University), Shahjahanpur, U.P. 242001, India

hasnatgfc@rediffmail.com

Received 3 November 2015 / Accepted 20 November 2015

\begin{abstract}
Boron containing polyesteramide synthesized from Jatropha curcas seed oil, a renewable, non-edible and abundantly available resource has been found to show improved performances as coating materials. However, curing of the resins at elevated temperature restrict its viability in many service conditions, especially where baking are not possible. With a view towards the use of boron containing polyesteramide derived from Jatropha curcas seed oil and to cure at ambient temperature, toluylene diisocyanate (TDI) was incorporated in the resin in varying proportion to obtain urethane modified boron containing polyesteramide resins. The latter resins were found to cure at room temperature. The effects of amount of TDI on the drying time were also investigated. The synthesized resins characterized by physicochemical and spectral analyses. The film properties of the ambient cured urethane-modified boron containing polyestramides were also studied.
\end{abstract}

Keywords: Jatropha curcas, Seed oil, Urethane, Boron polyesteramides

\section{Introduction}

Syntheses of polymers from renewable resources have attracted the attention of academicians and scientist due to the fast depletion of petrochemical stock and inflated prices ${ }^{1-3}$. Furthermore, environmental legislations also force to search bio-based alternatives ${ }^{4,5}$. Among different bio-based renewable resources, vegetable oil of different seeds has served as viable alternatives due their low toxicity, inherent biodegradability and easy availability ${ }^{4,6,7}$. Numerous vegetable oils like soybean, castor, sunflower and linseed have been utilized for the preparations of valuable polymers like alkyds ${ }^{4}$, polyesteramides ${ }^{8}$, polyurethanes ${ }^{8}$, polyamides ${ }^{4,8}$ and many others. However among these oils most of them are edible and some of them also posses' medicinal values. Therefore, it is desirable to utilize the renewable but non-edible seed oils in the syntheses of useful polymers which not only reduce the scarcity of feed stock but also provide suitable utilization of meagerly utilized materials.

Jatropha curcas is a medium sized tree widely grown in India ${ }^{9}$. It is mainly found on the sides of roads, railways tracks and also cultivated by the farmers on sides of farmlands. 
Jatropha curcas tree yielded non edible seeds which contain about $48 \%$ triglyceride oil of saturated and unsaturated fatty $\operatorname{acid}^{9}$. Literature survey reveals that Jatropha curcas seed oil (JCSO) is abundantly available in the country and only small fraction of the total production is used as biodiesel in the rural areas.

The meager utilization of the abundantly available Jatropha Curcas seed oil (JCSO) prompted the scientists and technologists to develop way to fully utilize it in making valuable polymeric materials ${ }^{10,11}$. In our earlier publications we have attempted to synthesize the polyesteramide (JCPEA) and boron containing polyesteramide (JCBPEA) from this seed oil $^{12,13}$. Polyesteramide resins are amide modified alkyd known for improved performances over traditional alkyds. The performances of the resin further improved significantly by incorporating the boron ${ }^{12}$. Curing of the JCPEA and JCBPEA at elevated temperature restrict their applications in many cases especially where baking is not possible. Furthermore, curing of the resins at high temperature is a tedious as well as energy consuming process. In this work we attempted to develop urethane-modified boron containing polyesteramide (JCBPEAU) from JCSO with the objective of using a precursor obtained from a renewable and abundantly available resource with improved performances cured at ambient temperature. Polyurethane resins are well recognized for their excellent adhesion, flexibility, weather resistance and ambient temperature curing ${ }^{14,15}$. The synthesized resin has improved hybrid properties of boron containing polyesteramide and urethane along with curing at room temperature. The synthesized polymer was characterized by measuring the physicochemical properties and spectroscopic analyses.

\section{Experimental}

The seeds of Jatropha curcas were collected from the G.F. College campus, Shahjahanpur, U.P., India. The oil was extracted from the dried and crushed seeds through the soxhlet apparatus. Petroleum ether (b.p. $60-80^{\circ}$ ) was used as a solvent. Phthalic acid, diethyl ether, methanol, boric acid (Merck, India), toluylene-2,4-di-isocyante (Merck, Germany) and diethanol amine (S.D. Fine Chemicals, India) were of analytical grade.

\section{Syntheses}

N,N-Bis (2-hydroxy ethyl) Jatropha curcas oil fatty amide (HEJCA), Jatropha curcas polyesteramide (JCPEA) and Jatropha curcas Boron containing polyesteramide (JCBPEA)

HEJCA, JCPEA and JCBPEA were synthesized and characterize as per previously reported $\operatorname{method}^{14}$.

\section{Synthesis of Jatropha curcas urethane-modified boron containing polyesteramide (JCBPEAU)}

JCBPEA was dissolved in xylene as solvent treated with different amount of toluylene diisocyanate (TDI) in a four necked round flask fitted with condenser, nitrogen inlet tube, thermometer and a mechanical stirrer. The extent of loading of TDI in per hundred of resin (phr) is provided in the Table 1 . The reaction contents were heated at $140 \pm 5{ }^{\circ} \mathrm{C}$ under stirring and continued till the completion of the reaction. The progress of the reaction was monitored by thin layer chromatography (TLC) at regular intervals. After the completion of reactions, the reaction contents were allowed to cool at room temperature under stirring. The products were taken out from the reaction flask and excess of solvent were removed in a rotary evaporator under reduce pressure to obtain JCBPEAPU resins. 
Table 1. Physicochemical, mechanical and chemical/corrosion resistance properties of JCBPEAU resins

\begin{tabular}{|c|c|c|c|c|}
\hline Resin $\operatorname{code}^{*} \rightarrow$ & JCBPEAU-2 & JCBPEAU-4 & JCBPEAU-6 & JCBPEAU-8 \\
\hline \multicolumn{5}{|c|}{ Physicochemical analyses } \\
\hline Color value & 5 & 5 & 5 & 5 \\
\hline Specific gravity & 0.989 & 0.991 & 0.992 & 0.994 \\
\hline Refractive index & 1.564 & 1.568 & 1.572 & 1.574 \\
\hline Inherent viscosity & 0.682 & 0.686 & 0.694 & 0.734 \\
\hline Iodine value & 21.18 & 20.62 & 20.22 & 19.82 \\
\hline \multicolumn{5}{|c|}{ Physicomechanical properties } \\
\hline $\begin{array}{l}\text { Dry to touch time } \\
\text { (min) }\end{array}$ & 35 & 30 & 25 & 25 \\
\hline Bending test (1/8 in) & Passes & Passes & Passes & Passes \\
\hline Gloss at $45^{\circ}$ & 82 & 86 & 88 & 88 \\
\hline $\begin{array}{l}\text { Impact resistance } \\
(\mathrm{lb} / \mathrm{in})\end{array}$ & 100 & 150 & 200 & 200 \\
\hline Scratch hardness $(\mathrm{Kg})$ & 1.80 & 2.40 & 2.70 & 2.70 \\
\hline \multicolumn{5}{|c|}{ Chemical Resistance/corrosion resistance ${ }^{* *}$} \\
\hline $\mathrm{H}_{2} \mathrm{O}$ (10 days) & $\mathrm{E}$ & $\mathrm{E}$ & $\mathrm{E}$ & $\mathrm{E}$ \\
\hline $\mathrm{HCl}(5-\mathrm{wt} \%) 10$ days & $\mathrm{C}$ & $\mathrm{D}$ & $\mathrm{E}$ & D \\
\hline $\mathrm{NaOH}(5-\mathrm{wt} \%) 3 \mathrm{hrs}$ & A & B & $\mathrm{C}$ & B \\
\hline $\begin{array}{c}\mathrm{NaCl}(3.5-\mathrm{wt} \%) \\
\text { days }\end{array}$ & B & $\mathrm{D}$ & E & D \\
\hline
\end{tabular}

$*$ last digit of resin code indicates phr of TDI, **A= Film detached; $B=$ Film partially detached; $C=$ Loss in gloss; $D=$ Slight loss in gloss; $E=$ Unaffected

\section{Characterization}

Physicochemical characterizations of the polymeric resins like refractive index, specific gravity, and iodine value were measured as per standard reported laboratory methods ${ }^{5,13}$. The structural elucidation of polymeric resin was carried out by spectral analyses. The FTIR spectrum of JCBPEAU was taken on Perkin Elmer 1750 FT-IR spectrometer (PerkinElmer Cetus Instruments, Norwalk, CT) using a $\mathrm{NaCl}$ cell. ${ }^{1} \mathrm{H}$ NMR and ${ }^{13} \mathrm{C}$ NMR spectra of the resin were recorded on JEOL GSX $300 \mathrm{MHz}$ FX-1000 spectrometer using deuterated chloroform as a solvent and tetramethylsilane (TMS) as an internal standard.

\section{Preparation of coatings}

Coatings of JCBPEAU resins were developed on mild steel strips, $70 \times 25 \times 1 \mathrm{~mm}$ size for

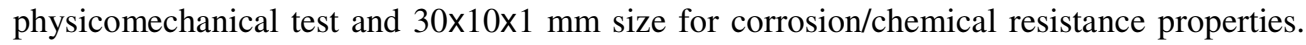
The mild steel strips were polished on various grade of silicon carbide papers, then washed with distilled water, degreased with alcohol and carbon tetrachloride. Finally strips were dried under vacuum for several hours. The coatings of JCBPEAU resins were developed on these specimens by brush technique using solution of $60 \mathrm{wt} \%$ of resins and allowed cure at room temperature in dust free environment. Dry to touch and dry to hard time for JCBPEAU resins containing different phr of TDI given in Table 1. Coating thickness of the polymer films were measured by elcometer and were found between $80 \pm 10 \mu \mathrm{m}$. The coated samples were evaluated for the scratch hardness (BS 3900), bending test on conical mandrel, and impact resistance (IS: 101 part 5/s.31988) tests. Chemical/corrosion resistance tests of the coatings were performed in water, acid $(5 \mathrm{wt} \% \mathrm{HCl})$ and alkali $(5 \mathrm{wt} \% \mathrm{NaOH})$, by pouring 
their solution in 3 "- diameter porcelain dishes and dipping the coated specimens in aforementioned media. Periodic examinations were performed until coating showed visual evidence of softening, deterioration in gloss, discoloration or weight loss (Table 1). The salt spray test (ASTM B117-94) was also performed in a salt mist chamber containing $3.5 \mathrm{wt} \%$ $\mathrm{NaCl}$ solutions.

\section{Results and Discussion}

Figure 1 show the scheme for the preparation of HEJCA, JCPEA, JCBPEA and JCBPEAU. Triglyceride oil reacts with diethanol amine in presence sodium methoxide to give HEJCA. The HEJCA undergo polycondensation reaction with phthalic acid to produce JCPEA. The carboxylic end of JCPEA coupled with the $\mathrm{B}(\mathrm{OH})_{3}$ and produces JCBPEA. The JCBPEA contain hydroxyl groups at terminals and behave as diol and tailored to a series of urethane modified JCBPEA resins by reaction with TDI in different phr. Table 1 shows an increase in specific gravity, refractive index, viscosity and decrease in the iodine value with the increase phr of TDI, due to increase in molar masses of JCBPEAU resins.
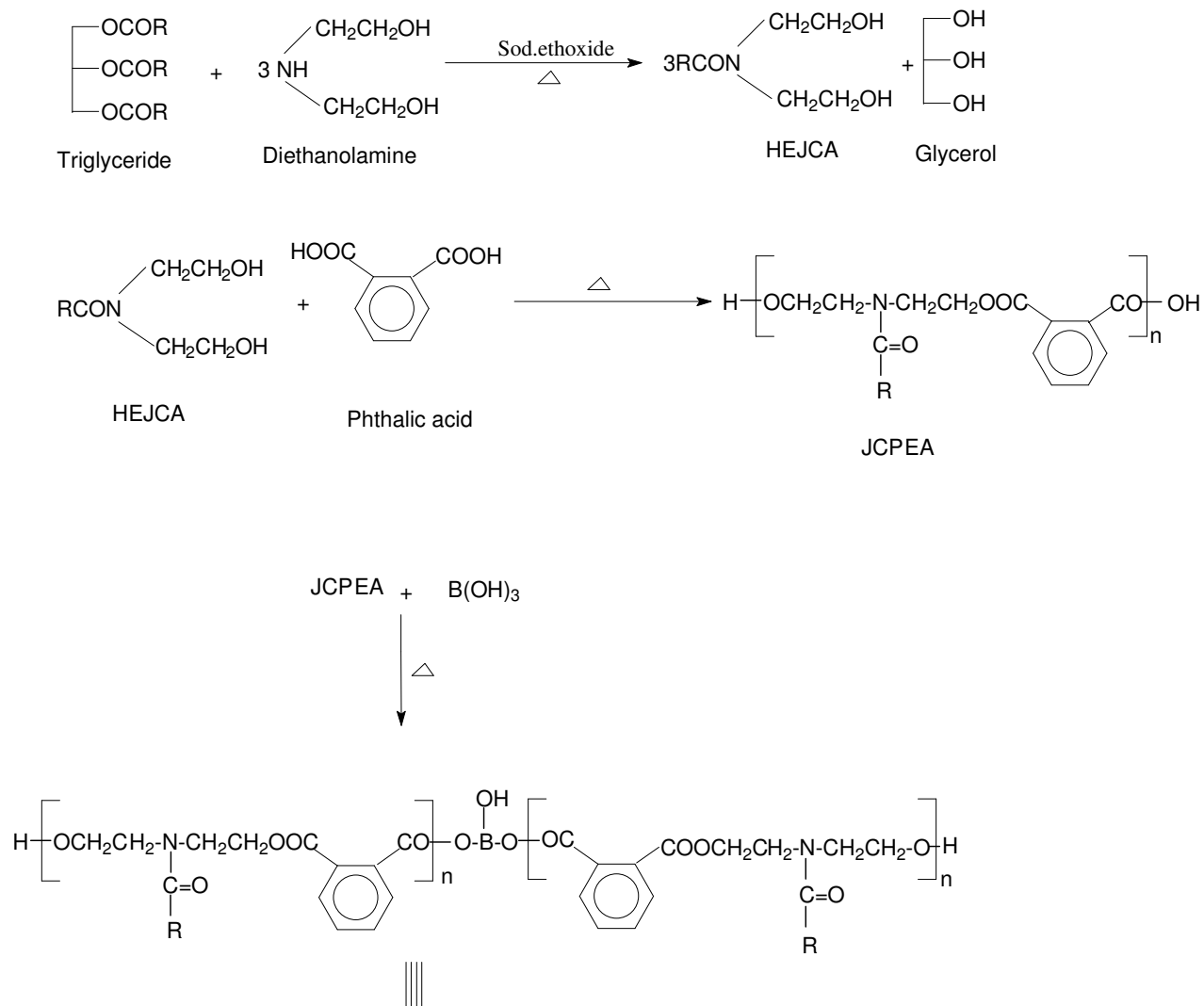<smiles>O[14CH2]O[13C@@H](O)[14CH2]O</smiles> 


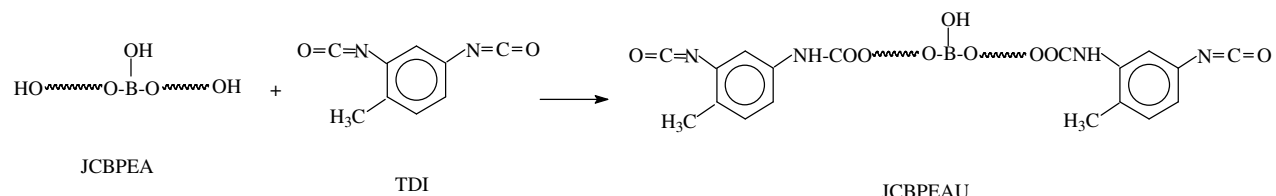

Figure 1. Synthesis of Jatropha curcas urethane-modified boron containing polyesteramide (JCBPEAU)

The FT-IR spectrum of JCBPEAU shows the characteristic bands at $3648-3112 \mathrm{~cm}^{-1}$ due to $\mathrm{OH}$ and $\mathrm{NH}$ groups. The absorption bands for $\mathrm{CH}_{2}$ of fatty amide chain asymmetric and symmetric stretching appears at $2978,2886 \mathrm{~cm}^{-1}$. The band at $2276 \mathrm{~cm}^{-1}$ is attributed to the free $-\mathrm{NCO}$ groups. The carbonyl of ester, urethane and amide groups appear at $1756 \mathrm{~cm}^{-1}$, $1720 \mathrm{~cm}^{-1}$ and $1682 \mathrm{~cm}^{-1}$ respectively. The $\mathrm{NH}$ deformation mode appears at $1567 \mathrm{~cm}^{-1}$, whereas the bands at $1552-1532 \mathrm{~cm}^{-1}$ and $778-708 \mathrm{~cm}^{-1}$ due the benzene rings. ${ }^{1} \mathrm{H}$ NMR spectrum of the JCBPEAU shows the peaks at $\delta=7.84-7.96 \mathrm{ppm}$ due to NH of urethane. The peaks at $\delta=7.24-8.64 \mathrm{ppm}$ due to aromatic rings, the multiplet peak for protons of double bonded carbons appears at $\delta=5.34-5.42 \mathrm{ppm}, \mathrm{CH}_{3}$ of TDI appears at $\delta=2.24 \mathrm{ppm}$, broad peak for chain $-\mathrm{CH}_{2}$ - appears at $\delta=1.24-1.38 \mathrm{ppm}$, terminal $-\mathrm{CH}_{3}$ appears at $\delta=0.93 \mathrm{ppm}$. ${ }^{13} \mathrm{C}$ NMR spectrum of JCBPEAU shows the peaks at $\delta=175.2 \mathrm{ppm}, 164.4 \mathrm{ppm}$ and 156.8 ppm for the carbonyls of ester, amide and urethane. Closely spaced peaks at $\delta=128.4-138.6$ ppm due to carbons of aromatic rings of phthalic acid and TDI, where as double bounded carbons of fatty amide appears at $\delta=127.8-130.6 \mathrm{ppm}$. Peaks for chain $\mathrm{CH}_{2}$ of fatty amide appears at $\delta=24.6-31.4 \mathrm{ppm}$ while $\mathrm{CH}_{3}$ of TDI and terminal of fatty amide appears at $\delta=$ 18.2 and $15.8 \mathrm{ppm}^{\mathrm{pespectively}}{ }^{14}$.

\section{Coating properties}

Coatings of JCBPEAU containing different phr of TDI were developed on standard size of mild steel strips for physicomechanical and chemical/corrosion resistance performances. Table 1 shows that on increasing the TDI content drying time initially decreases and become almost constant after 6 phr loading. Furthermore, JCBPEAU obtained by loading of TDI above than $10 \mathrm{phr}$ becomes unbrushable, loss the fluidity and required high amount of organic solvents for application, which is not suitable for coating materials as well as from environment point of view ${ }^{15}$. Curing occurs through the secondary reaction of the moisture with the terminal NCO groups (ASTM type 2) ${ }^{16}$. Scratch hardness of polymer films increases with the increasing the amount of TDI. Coated samples pass the impact resistance test $150 \mathrm{lb} / \mathrm{in}$, reasonably due to presence of urethane linkages in addition to other polar groups which provides sufficient adhesion to polymeric resins. Presence of urethane linkages as well as long fatty amide chain in the polymer chain conferred the high flexibility to the coatings, coated samples pass the bending test on $1 / 8$ conical mandrel, no visual cracks were observed. The same can be attributed to high gloss value and other physicomechanical performances. The coated samples show the good performances in the humid, acidic and salty environments. This is due to the presence of urethane, fatty amide chain as well as boron in the polymer chain, which provide well-adhered coating system.

\section{Conclusion}

Synthesis of urethane modified boron containing polyesteramide from Jatropha curcas seed oil can be cured at room temperature. Curing at room temperature provide viable utility to the polymeric resin as it has ability to use where baking is not possible and also avoid the 
multi-step and energy consuming process. The study reveals that the synthesis of the JCBPEAU provides a more profitable and suitable route for the utilization of Jatropha curcas seed oil a renewable and abundantly available resource in the area of surface coatings.

\section{Acknowledgement}

The authors would like to thank the authorities of G. F. College, Shahjahanpur, UP, India for providing necessary facilities for carrying out this study and Mr. A. Wahab for valuable suggestions.

\section{References}

1. Ahamad S, Ahmad S A and Hasnat A, Chem Sci Trans., 2015, 4(4), 1047-1053; DOI:10.7598/cst2015.1105

2. Zafar F, Ashraf S M and Ahmad S, Reactive Functional Polym., 2007, 67(10), 928935; DOI:10.1016/j.reactfunctpolym.2007.05.018

3. Ahamad S, Imran G, Ahmad S A and Hasnat A, Chem Sci Trans., 2015, 4(3), 858864; DOI; $10.7598 /$ cst2015.1060

4. Islam M R, Beg M D H and Jamari S S, J Appl Polym Sci., 2014, 131(18), 4078740799; DOI:10.1002/app.40787

5. Ahmad S, Ashraf S M, Naqvi F, Yadav S and Hasnat A, Prog Org Coat., 2003, 47(2), 95-102; DOI:10.1016/S0300-9440(03)00015-8

6. Yakushin V, Stirna U, Bikovens O, Misane M, Sevastyanova I and Vilsone D, Materials Sci., 2014, 20(3), 277-282; DOI:10.5755/j01.ms.20.3.4532

7. Imran G, Ahamad S and Ahmad S A, Orient J Chem., 2015, 31(1), 553-556.

8. Guner F S, Yogci Y and Erciyes A T, Prog Polym Sci., 2006, 31(7), 633-670; DOI:10.1016/j.progpolymsci.2006.07.001

9. Ambastha S P, Useful Plants of India, CSIR, New Delhi, 1986.

10. Patel V C, Varughese J, Krishnamoorthy P A, Jain R C, Sigh A K and Ramamoorty M, J Appl Polym Sci., 2008, 107, 1724-1729; DOI:10.1002/app.27195

11. Alam M, Akram D, Sharmin E, Zafar F and Ahmad F, Arabian J Chem., 2014, 7, 469-479; http://dx.doi.org/10.1016/j.arabjc.2013.12.023

12. Imran G, Ahamad S, Altaf I and Ahmad S A, Chem Sci Trans., 2015, 4(4), 10071012; DOI:10.7598/cst2015.1103

13. Ahmad S, Ashraf S M, Kumar S, Alam M and Hasnat A, Indian J Chem Technol., 2005, 12, 193-197.

14. Silverstein R M, Bassler G C and Morril T C, Spectroscopic Identification of Organic Compounds, $5^{\text {th }}$ Edn., (John Wiley \& Sons, New York), 1991.

15. Yadav S, Zafar F, Hasnat A and Ahmad S, Prog Org Coat., 2009, 64(1), 27-32; DOI:10.1016/j.porgcoat.2008.07.006

16. Sounders K J, Organic Polymer Chemistry, $2^{\text {nd }}$ Edn., (Chapman and Hall, USA) 1988. 